Psychology \& Sexuality

Vol. 3, No. 3, September 2012, 226-243

Routledge

Taylor \& Francis Group

\title{
Rural location and exposure to minority stress among sexual minorities in the United States
}

\author{
Eric Swank ${ }^{\mathrm{a} *}$, David M. Frost ${ }^{\mathrm{b}}$ and Breanne Fahs ${ }^{\mathrm{c}}$ \\ ${ }^{a}$ Department of Sociology, Social Work and Criminology, Morehead State University, Morehead, \\ KY, USA; ${ }^{b}$ Heilbrunn Department of Population and Family Health, Columbia University, \\ New York, NY, USA; ${ }^{c}$ Women and Gender Studies Program, Arizona State University, Glendale, \\ AZ, USA
}

(Received 31 August 2011; final version received 3 May 2012)

\begin{abstract}
Recently, there has been an increase in the number of studies on minority stress among sexual minorities. Few of these studies have explored the ways in which regional or spatial factors influenced the amount of minority stress that lesbians, gay men and bisexuals (LGBs) endure. To see if living in rural and small towns creates stressful social environments for LGBs in the United States, this study analysed the associations between location and three distal minority stress outcomes, as well as feelings of connectedness to the LGB community. In a sample of self-identified LGBs $(N=285)$, this study found that rural contexts and small towns often presented harsher social climates for sexual minorities compared with urban locales. LGBs who resided in rural areas tended to feel less connected to LGB communities and experienced higher levels of felt stigma and enacted discrimination. Small town inhabitants displayed some similar patterns, but also reported lower levels of enacted discrimination than expected. Living in Southern states subjected LGBs to more discrimination and less satisfactory connections to LGB communities.
\end{abstract}

Keywords: stigma; discrimination; minority stress; sexual minority; rural environment

Structurally and interpersonally, discrimination against lesbian, gay and bisexual (LGB) individuals takes many forms. Homophobia can manifest itself through physical violence and language that chastises and belittles both homosexuality and non-normative gender behaviour. More subtly, homophobia and heteronormativity inform many insidious practices that privilege heterosexuality. Whether via the lack of legal marital rights or the assumption that heterosexuality must be enforced, LGBs often endure hostile environments that monitor and penalise homosexual behaviour in the United States.

LGB individuals' experiences of stigma, prejudice and discrimination, which result from heteronormativity, have been usefully conceptualised as constituting minority stress (Brooks, 1981; DiPlacido, 1998; Hatzenbuehler, 2010; Meyer, 2003a, 2003b; Rosario, Schrimshaw, Hunter, \& Gwadz, 2002). Minority stress theory is based on social stress theory (Dohrenwend, 2000; Pearlin, 1999), which posits that stressors constitute any factors or conditions that require individuals to adapt to changes intrapersonally, interpersonally or in their environments (Meyer, 2003a; Pearlin, 1999). Factors such as expectations of

*Corresponding author. Email: e.swank@moreheadstate.edu

ISSN 1941-9899 print/ISSN 1941-9902 online

(C) 2012 Taylor \& Francis

http://dx.doi.org/10.1080/19419899.2012.700026

http://www.tandfonline.com 
rejection, concealment of a stigmatised identity, internalisation of negative social beliefs about one's social groups or social identity and experiences of discrimination (both acute events and chronic everyday mistreatment) constitute stressors. These factors stem from and reaffirm a hostile everyday living environment for LGBs, thus creating an environment characterised by minority stress.

Meyer (2003a) posited that minority stressors can be usefully thought of on a continuum of proximity to the self. Stressors most distal to the self are objective stressors based primarily on the environment, such as prevailing stereotypes, prejudice and discrimination. In this category, hate crimes and interpersonal violence directed towards LGB individuals figure centrally, primarily because of the devalued status of sexual minorities within heteronormative cultures. Distal minority stressors lead to more proximal and subjective appraisals of the environment as threatening and resulting expectations of rejection. Most proximal to the self is one's internalisations of negative social attitudes towards one's minority group (e.g. internalised homophobia).

Minority stress processes have been hypothesised to create strain on individuals' ability to adapt to, and function in, their everyday environments and are therefore associated with lowered well-being and impaired mental health. Mental health disparities between heterosexuals and LGBs likely stem from differential exposure to minority stress processes (Meyer, 2003a).

LGB individuals cope with minority stress in a variety of ways. For example, feeling connected to an LGB community is considered a group-level coping resource for dealing with the negative effects of minority stress (Frost \& Meyer, 2012; Kertzner, Meyer, Frost, \& Stirratt, 2009; Meyer, 2003a). A sense of connectedness allows LGB individuals to experience self-empowerment. Specifically, feeling part of a community of similar others allows LGBs to make positive social comparisons to other people like them, instead of making negative comparisons, based on heterosexist stigma, to members of the out-group (Crocker \& Major, 1989; Herek \& Glunt, 1995; Meyer, 2003a). For these reasons, connectedness to the LGB community can play an ameliorative role in the relationship between minority stress and mental health (Major \& O'Brien, 2005; Meyer, 2003a). Moreover, the survival of discrimination, when combined with other key interpretative schemas, can push LGB individuals into greater amounts of political activism for LGB rights (Hyers, 2007; Jennings \& Andersen, 2003; Swank \& Fahs, 2011; Taylor, Kimport, Van Dyke, \& Andersen, 2009).

\section{Location and sexual stigma}

Urban sociologists like Wirth (1938) and Fischer (1975) were some of the early theorists who conceptualised that nations, regions and localities can distinguish their cultures from one another through the historical interplay of many social processes (e.g. state interventions, amount of industrialisation, migration practices, type of social networks available). Rural areas, or spaces that have high land-to-human ratios and an economic dependence on farming, mining and forestry, have often been conceptualised as communities that prize cultural homogeneity, localism, religiosity and 'traditional values' (Miller \& Laluff, 1981). In contrast, Wirth (1938) argued that the 'urban way of life' generally disrupts ethnocentric and authoritarian perspectives. Due to macro issues of city size, population density and greater cultural heterogeneity, city dwellers regularly encounter social systems that transmit new, unique and incompatible moral messages. To cope with diverse and sometimes contradictory social cues, city dwellers must learn how to respond to a wider range of opinions as they try to reconcile competing moral and behavioural expectations. This adaptation then normalises flexibility in thought and a greater tendency to accept practices that could be considered unconventional or strange in more rural and small town settings. 
Adding to these contextual factors are possible compositional effects. That is, cities or regions may hold higher concentrations of people who possess the traits associated with liberalism - such as higher education levels, less religious fundamentalism or general inclination to not see diversity as a threat (Adamczyk \& Pitt, 2009; Moore \& Vanneman, 2003; Van Dyke, Soule, \& Widom, 2001). In fact, Johnson and Stokes (1984) contended that the greater conservativism of Southern communities is partly due to greater prevalence of personal piety (e.g. prayer) and the acceptance of orthodox-fundamentalist religious beliefs (the Bible is inerrant, the ubiquity of human sinfulness or the fear of eternal damnation at the hands of a punitive God).

Studies that link heterosexism to regional variation have mostly followed two approaches. When addressing sexual prejudice of heterosexuals, some studies have explored the possibility of gender and sexuality attitudes being spatialised in the United States (Bolzendahl \& Myers, 2004; Carter \& Borch, 2005; Rice \& Coates, 1995; Twenge, 1997). Traditional gender and sexuality scripts are expressed more frequently by people who reside in a small town or rural communities (Bolzendahl \& Myers, 2004; Herek, 2002; Johnson, 1999; Konrad \& Harris, 2002; Loftus, 2001; Pratte, 1993; Rhodebeck, 1996; Schulte, 2002). Other studies contend that spatial differences also appear within metropolitan areas as suburban heterosexuals seem less supportive of same-sex marriage rights than centre-city heterosexuals (Loftus, 2001). Conversely, other studies have downplayed the role of urbanity because they could not detect a significant urban-rural divide in homophobic sentiments (Herek \& Glunt, 1993; Lemell \& Battle, 2004; Marsiglio, 1993).

Other prejudice studies have looked for regional subcultures differences as well. Akin to the Southern subculture of violence studies in criminology (Ellison, 1991; Nisbett \& Cohen, 1996), and 'Southern exceptionalism' in religious studies (Chalfant \& Heller, 1991; Woodberry \& Smith, 1998), some studies have examined the Southern effect on gender norms in the United States. Accordingly, people who reside in the 'Deep South' (e.g. Mississippi, Georgia, South Carolina, Tennessee, Alabama) were more likely to endorse traditional conceptions of appropriate male and female behaviours (Bolzendahl \& Myers, 2004; Carter \& Borch, 2005; Eldridge, Mack, \& Swank, 2006; Johnson \& Stokes, 1984; Konrad \& Harris, 2002; Marquart, Nannini, Edwards, Stanley, \& Wyman, 2007; Powers et al., 2003; Rice \& Coates, 1995; Twenge, 1997).

\section{Location and minority stress}

The empirical literature on how discrimination and minority stress vary across community contexts is sparse. Since the mid-1990s, there has been a small upsurge in the number of qualitative studies of rural sexualities (Barton, 2010; Bell \& Valentine, 1995; Black \& Rhorer, 2001; Boulden, 2001; Cody \& Welch, 1997; Fellows, 1998; Gottschalk \& Newton, 2009; Gray, 2009; Kramer, 1995; McCarthy, 2000; Oswald \& Culton, 2003; Tiemann, Kennedy \& Haga, 1998; Williams, Bowan \& Horwath, 2005; Yarbrough, 2003). Ruralbased LGBs overwhelmingly described living in bleak and inhospitable social climates. Their narratives often discuss a hostile rural context that forced sexual minorities into silence, social isolation and fear of moral condemnation and hate crimes. In essence, these studies depict rural families, workplaces and churches as oppressive institutions to flee from, while cities are positioned as providing better contexts for healthy sexual minority identity development.

Quantitative studies about minority stress variation by region offer less consistent results than qualitative studies on this topic (Gonzalez, Miller, Solomon, Bunn \& Cassidy, 2009; Johnson, Jackson, Arnette \& Koffman, 2005; Kosciw, Greytak \& Diaz, 2009; Leedy \& Connolly, 2007; Waldo, Hessen-McInnis \& D’Augelli, 1998). An early Kinsey Report 
found that rural gay men lacked access to supportive LGB communities and often had clandestine same-sex sexual encounters with men who never considered themselves gay (Kinsey, Pomeroy \& Martin, 1948). A recent study of Canadian LGB adolescents noted that rural youths were confronted more with verbal teasing and physical assaults than their metropolitan counterparts (Poon \& Saewyc, 2009). Another national study of LGB high-school students found that students who attended urban schools heard less homophobic remarks and dealt with less sexual harassment related to sexual identity than those who attend schools outside of urban areas (Kosciw et al., 2009). However, suburban and Southern students did not report less homophobic bullying than rural and Midwestern students. Other survey-based studies partially confirmed and rejected aspects of the rural toxicity argument. A recent sample from Wyoming noted that lesbians in smaller towns faced greater levels of public discrimination than those in larger cities (Leedy \& Connolly, 2007). However, regional differences were not present for gay men, and small-town lesbians did not face greater levels of homonegativity from parents, siblings and friends. Similarly, rural lesbian mothers experienced more cases of public harassment and rejection than urban lesbian moms, but the spatial differences disappeared when addressing homophobic comments by relatives (Puckett, Horne, Levitt \& Reeves, 2011). Also, some evidence indicates that community size does not predict the reported amounts of social stigma for LGBs living with AIDS, yet rural lesbians and small-town gay men were more afraid to disclose their sexual identity than urban LGBs (Gonzalez et al., 2009).

Some studies have detected no urban or rural effects on the experience of minority stress for LGBs. For example, a study of LGB senior citizens in nursing homes found that community size did not predict the amount of discrimination they recognised from administrators, staff and other residents (Johnson et al., 2005), and a study of LGB college students found that urban and rural respondents reported similar levels of verbal or physical harassment, access to the LGB community and familial acceptance of their sexual identity (Waldo et al., 1998). Finally, place of residency was unrelated to levels of internalised homophobia, stigma consciousness and the amount of 'outness' among urban and rural lesbian mothers (Puckett et al., 2011).

In the light of these inconsistent quantitative findings on location and minority stress, additional research is necessary to determine whether the qualitative differences in experiences of minority stress in rural and urban locations can be demonstrated quantitatively and on a larger scale. This is necessary given that a separate body of research has argued that geographic differences in the magnitude of disparities in mental health between LGBs and heterosexuals are indicative of potential place-based differences in minority stress (Lewis, 2009). Rural LGB youth are at greater risk for mental health problems such as depression, suicidal ideation and substance use compared with urban LGB youth (Galliher, Rostosky, \& Hughes, 2004; Poon \& Saewyc, 2009). Although these location-based differences in mental health provide some evidence for the negative effects of minority stress on health for rural LGBs, few recent studies have explicitly tested whether LGBs in rural locations are exposed to greater minority stress than LGBs in urban or suburban locations. To fully analyse the relationship between the rural locations and the minority stress process, one must test how living in a rural location results in increased exposure to minority stress (Meyer, Schwartz, \& Frost, 2008).

Because sexual stigma (and related prejudices towards gender non-conformity) is probably higher in rural locations, rural LGBs could be at risk for greater exposure to minority stress than urban or suburban LGBs (Bell \& Valentine, 1995; Kosciw et al., 2009; Leedy \& Connolly, 2007). LGBs are often drawn to urban centres because they often provide visible LGB communities and are often centred on community centres and nightlife. Rural 
locations often lack visible LGB communities, although resources dedicated to the promotion of LGB health and well-being are often scarce or non-existent (Gonzalez et al., 2009; Oswald \& Culton, 2003; Tiemann et al., 1998; Willging, Salvador, \& Kano, 2006). Rural LGBs may therefore lack access to community coping resources that are theorised to buffer the negative effects of minority stress, such as psychological connectedness to LGB communities (Frost \& Meyer, 2012; Kertzner et al., 2009; Meyer, 2003a).

\section{Aims and hypotheses}

This study aimed to test critical components of both the minority stress and the social stress models. More specifically, we hypothesised that living in rural locations would result in excess exposure to minority stressors and decreased coping resources (Meyer et al., 2008). Specifically, we tested the hypothesis that LGBs living in rural locations would report greater minority stress than LGBs living in more suburban and urban communities. Additionally, given that previous research has identified the unique role of sexual stigma in Southern US culture (Gonzalez et al., 2009; Oswald \& Culton, 2003; Tiemann et al., 1998; Willging et al., 2006), we hypothesised that living in the Southern United States would increase exposure to minority stress compared with others living in non-Southern rural locations. In other words, living in a Southern region of the United States may result in added exposure to minority stress, above and beyond the exposure associated with living in a rural location alone. Finally, due to the lack of visible sexual minority populations and community resources available to LGBs in rural areas, we hypothesised that rural and Southern LGBs would report less psychological connectedness to an LGB community compared with urban and non-Southern LGBs.

\section{Method \\ Participants}

This online study analysed data from a sample of 285 LGB women and men recruited from throughout the United States in December 2007. Online surveys offer unique methodological advantages when studying LGB populations (Herek, 2009; Koch \& Emery, 2002; Riggle, Rostokwsky, \& Reedy, 2005) for several reasons. First, national random samples often fail to ask questions about sexual orientation and discrimination against sexual minorities. Second, the use of Internet listservs offers access to a national scope of potential respondents. Third, random phone or mail samples are difficult to obtain, in part because researchers vary the definition of who qualifies as LGB, and because complete lists of every LGB person in the United States do not exist. Fourth, convenience samples are often less representative since they attract participants that are too homogeneous (Faugier \& Sargeant, 1997) and disproportionally select those who are already 'out' and located solidly within the LGB community (Farquhar, 1999; Rhoads, 1997). Finally, in-person recruitment at LGB establishments like bars or clubs would be too selective as well (Riggle et al., 2005), as it would likely oversample those who are younger or more active in the LGB community, while excluding LGB people who are more closeted and those with disabilities (Butler, 1999).

Participants were recruited through 10 email listservs. Two of the listservs contained members of 'Fairness Alliances' that sought equality for LGB individuals. Memberships in these email groups were free and most of their participants resided in the Midwestern and Mid-Atlantic states, with the largest contingencies from Kentucky, Ohio, Indiana, Tennessee and West Virginia. The rest of the listservs provided less explicitly politically engaged networks. ${ }^{1}$ To select these email groups, we selected Yahoo groups that met three 
criteria. First, the group had to exist for explicitly social purposes (i.e. they did not mention anything political in the description of their listserv). Some of these groups concentrated on hobbies (e.g. 'Dykes on bykes' 'Gay Square Dancers' or 'GLBT Horselovers'), whereas others displayed support group qualities (e.g. 'Lavender Mothers' or 'Kentucky Pride'). Second, we excluded groups that seemed to serve as romantic or sexual matchmaking sites to avoid biasing the sample with an overrepresentation of single participants (we feared that the use of such sites would dramatically lessen the proportion of coupled respondents in the comparison group). Finally, to lessen problems of selection bias along spatial lines, we looked for groups that mentioned the regions that were most common in the political listservs (e.g. Queer Kentucky, Rural Pride of Tennessee or Gay in Ohio).

The cover letters sent via the listservs asked potential respondents to click on a link that took them to the study website. The letter solicited the involvement of adults who considered themselves lesbian, gay or bisexual. As expected, the letter stated that involvement in this project was anonymous and voluntary. The response rate to this letter was impossible to calculate since we did not have access to the number of people who belonged to each listserv.

The sample of 285 participants had a preponderance of males (58\% male) and a mainly Euro-American racial composition (79\% European American, 7\% Native American, 2\% African American, 1\% Asian American, 1\% Latino/a and 10\% 'refuse to answer'). Ages in the sample spanned a wide range, from age 18 to 75 , with $24 \%$ under age $30,54 \%$ ages $30-50$ and $22 \%$ ages $51-75(\bar{x}=39.75, \mathrm{SD}=12.19)$. The sample included a diverse array of incomes, including $10 \%$ below $\$ 20,000$ per year, $27 \% \$ 20,000-50,000$ per year, $25 \% 50,000-80,000$ per year and $31 \%$ over $\$ 80,000$ per year, with $8 \%$ being missing data. Similar to most samples of 'out' LGB participants, our sample was highly educated, with $3 \%$ having earned a high-school degree, $58 \%$ having some college or a bachelor's degree and $32 \%$ having a graduate degree. Participants tended to be distributed in many types of urban and rural spaces, with $26 \%$ residing in a large urban centre, $18 \%$ residing in a suburb of a large city, $18 \%$ residing in a mid-sized city, $23 \%$ residing in small towns and $9 \%$ living in rural areas. Because the majority of recruitment took place in the geographic South of the United States, $65.2 \%$ of participants lived in the South, $15.7 \%$ lived in the Midwest, $6.2 \%$ lived in the West and $4 \%$ lived in the East, with Kentucky, Ohio, Indiana, Tennessee and West Virginia representing the most respondents.

\section{Measures}

\section{Current location}

When identifying urban-rural distinctions, we asked the question 'What type of community do you currently reside in?' All of the close-ended responses dealt with the population density of that community (Hewitt, 1992): rural, small town, midsize city, suburban metropolitan and centre-city metropolitan. Participants' responses were recoded into a system of binary variables as each type of location may differ in the amount of minority stress. The centre-city metropolitan served as the referent group because our aims were to test the degree to which living in more rural locations represented added exposure to minority stress in relation to urban environments, which have been portrayed in the literature as accepting of LGB individuals.

An open-ended item asked 'What state do you currently live in?' Participants who typed Alabama, Arkansas, Florida, Georgia, Kentucky, Louisiana, Maryland, Mississippi, North Carolina, Oklahoma, South Carolina, Tennessee, Texas and Virginia were deemed Southern residency. 


\section{Minority stress variables}

This study measured several aspects of minority stress for LGB individuals: felt stigma, enacted discrimination and connectedness to an LGB community. By focusing on distal factors, each variable explored the extent to which sexual minorities encountered hostile or supportive social environments (see Table 1). All measures came from short versions of standardised scales and were coded such that higher scores indicated higher levels of the construct. Shortened versions of measures were used to minimise participant fatigue and survey dropout.

The three-item additive scale for felt stigma (adapted from Herek, 2009) dealt with perceptions that people in the participant's immediate environment were inclined to universally accept or demean homosexuality (Cronbach $\alpha=0.695$ ). By using a 5-point Likert scale, the first item measured the acceptance of sexual minorities in the workplace: 'At my workplace gays and lesbians are treated with respect' (strongly agree $=1$ ). The last two items dealt with homonegativity in larger contexts: 'I fear that most of my neighbors object to my homosexuality' and 'In my daily settings most people treat gays and lesbian with thinly veiled hostility' (strongly agree $=5$ ).

Enacted discrimination was measured with 18 questions that addressed how often participants had endured cases of explicit discrimination because of their perceived sexual identity (Herek, 2009). To address issues of physical violence, harassment and economic discrimination, participants were asked whether these events never occurred, happened once or twice or more times. Examples of physical violence questions included 'You were hit, beaten, physically attacked or sexually assaulted'. To address anti-gay harassment, respondents were asked to identify whether 'someone threatened you with violence' or 'someone verbally insulted you' because of LGB identity. To measure economic discrimination, respondents were asked whether they were 'denied or fired from a job' or 'prevented from moving into an apartment or house' because of their sexual identity. Items also differentiated between recent and long-term experiences of discrimination (nine items asked whether these events occurred in the last year, while nine addressed whether these events happened when they were 16 years old). The Cronbach $\alpha$ values for enacted discrimination in the last year and since 16 years old were 0.719 and 0.795 , respectively.

A sense of psychological connectedness to an LGB community was assessed using three items from the Connection to the Gay or Lesbian Community Scale (Szymanski, Chung, \& Balsam, 2001). The first item confirmed a desire to be part of an LGB community: 'Being a part of the lesbian and gay community is important to me'. The second and third items addressed an absence of being a member of the LGB community: 'I feel isolated and separated from other gays and lesbians' and 'I feel like I am the only gay or lesbian in most settings I am in'. In reversing the direction of the coding, higher scores for this additive scale scores suggest greater connection to the LGB community (Cronbach $\alpha=0.707$ ).

\section{Control variables}

Gender and race were treated as binary variables in which female and White were coded as 1 , whereas other responses were coded as 0 . Age was assessed with an open-ended question and we kept the data in interval form. Income was determined through a scale of family income in the last year (there were 10 categories that started at below $\$ 10,000$ and ended with above $\$ 151,000)$.

Analytical plan. A series of hierarchical ordinary least-squares (OLS) regression models tested the extent to which rurality of location and Southern location predicted exposure 


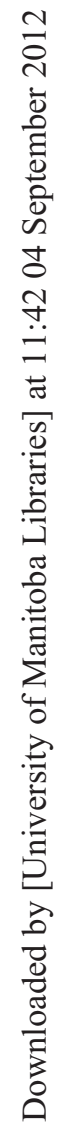

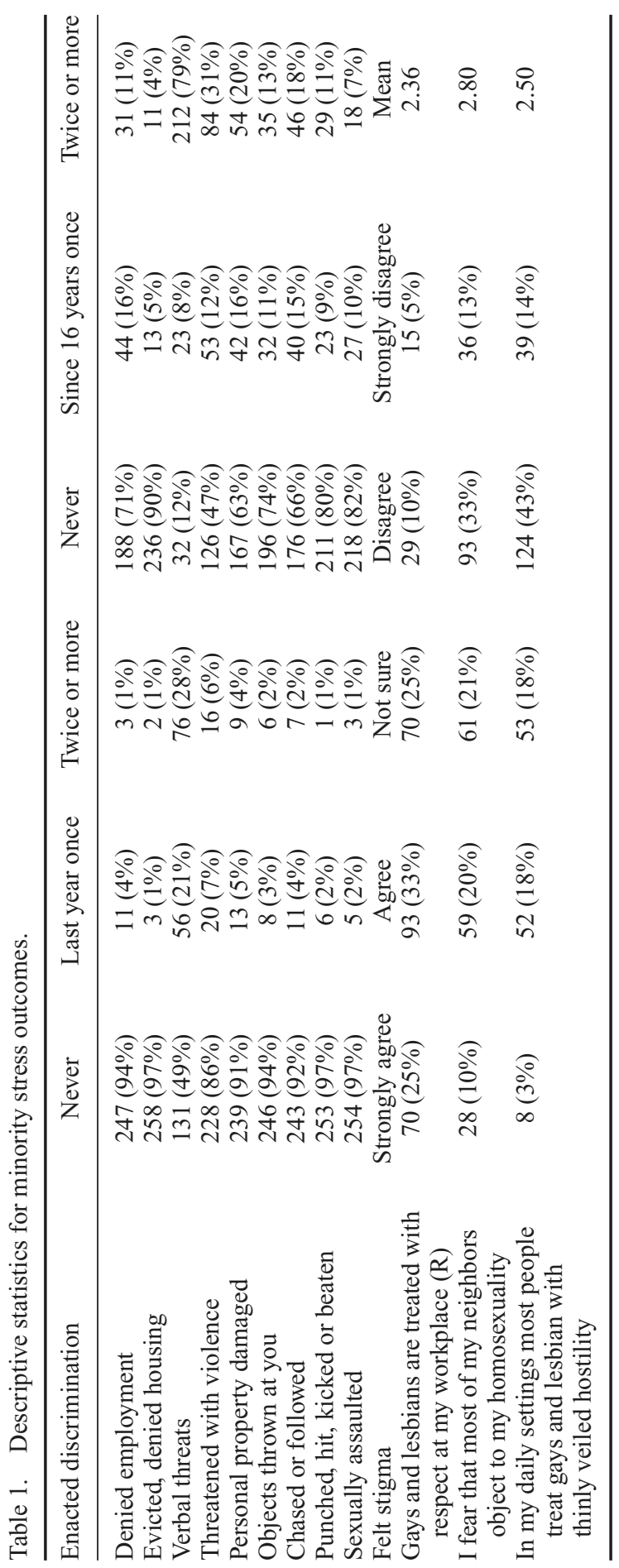


to the minority stress outcomes beyond demographic controls. The same approach examined the extent to which rurality of location and Southern location predicted psychological sense of connection to an LGB community. Variables were entered into the regression equations in two steps. Block 1 included the demographic control variables of gender $(1=$ male, $0=$ female), race/ethnicity $(1=$ white, $0=$ racial/ethnic minority), income and age. Block 2 added the location variables to the controls. Specifically, responses to the item measuring rurality of location were separated into a series of dichotomous variables representing (1) rural, (2) small town, (3) midsize city and (4) suburb of a large metropolitan centre. The centre city of a large metropolitan centre was treated as the referent group. The Southern location was added to the model in step (2) (non-Southern states served as the referent group). Our discussion of the explanatory results focused on the final models, because the standardised regression coefficients $(\beta)$ and $R^{2}$ change $\left(\Delta R^{2}\right)$ detect the spatial factors' incremental contributions to the variance explained for our four outcome variables.

\section{Results}

\section{Descriptive statistics for enacted discrimination and felt stigma}

Table 1 offers the descriptive statistics of enacted discrimination and felt stigma items. As a whole, felt stigma was more common than enacted discrimination (suggesting that implied heterosexism is more widespread than overt heterosexism). Cases of recent enacted stigma are relatively rare in this study, while most participants confronted the looming stress of threatened heterosexism. In the lifetime measures, almost nobody escaped heterosexist threats, and roughly two out of five have had their property damaged and over one-third had been chased or denied employment since 16 years old. Very high rates of sexual assault during a lifetime were also discovered (10\% were sexually assaulted once in their adulthood and $7 \% 2$ times or more).

While felt stigmatization was common for a large segment of the sample, its presence was not a universal norm. At least $30 \%$ of respondents noticed homophobia from neighbours and $21 \%$ felt that 'thinly veiled' instances of anger in the community. Nevertheless, the mean was below the mid-point of 3 because the distribution skewed towards the 'less' felt stigma categories. That is, 58\% of respondents 'agreed' or 'strongly agreed' that gays and lesbians were respected at their place of employment and between $46 \%$ and $57 \%$ disagreed to felt stigma items on neighbours and interactions in daily settings.

\section{Place variables and felt stigma-enacted discrimination}

Location-based differences in exposure to the minority stressors of stigma and discrimination are presented in Table 2. When exploring the proportion of variance explained by all of the variables, the $R^{2}$ and $\Delta R^{2}$ for the full model were significant in every case (Block 2). This suggests that the spatial and control variables together accounted for at least $9.3 \%$ of the variance in these discrimination outcomes and the spatial factors as a group significantly added between $4.7 \%$ and $6.7 \%$ of the variance explained beyond the control variables. When exploring specific factors, living in a rural location was significantly associated with increased exposure to stigma as well as more frequent experiences of discrimination since age 16 ( $\beta$ values ranged from 0.168 to $0.161, p<0.05$ ). Living in a small town was also associated with increased exposure to stigma compared with living in a city $(\beta=0.154, p<0.05)$ but not for any of the discrimination measures. Living in a 


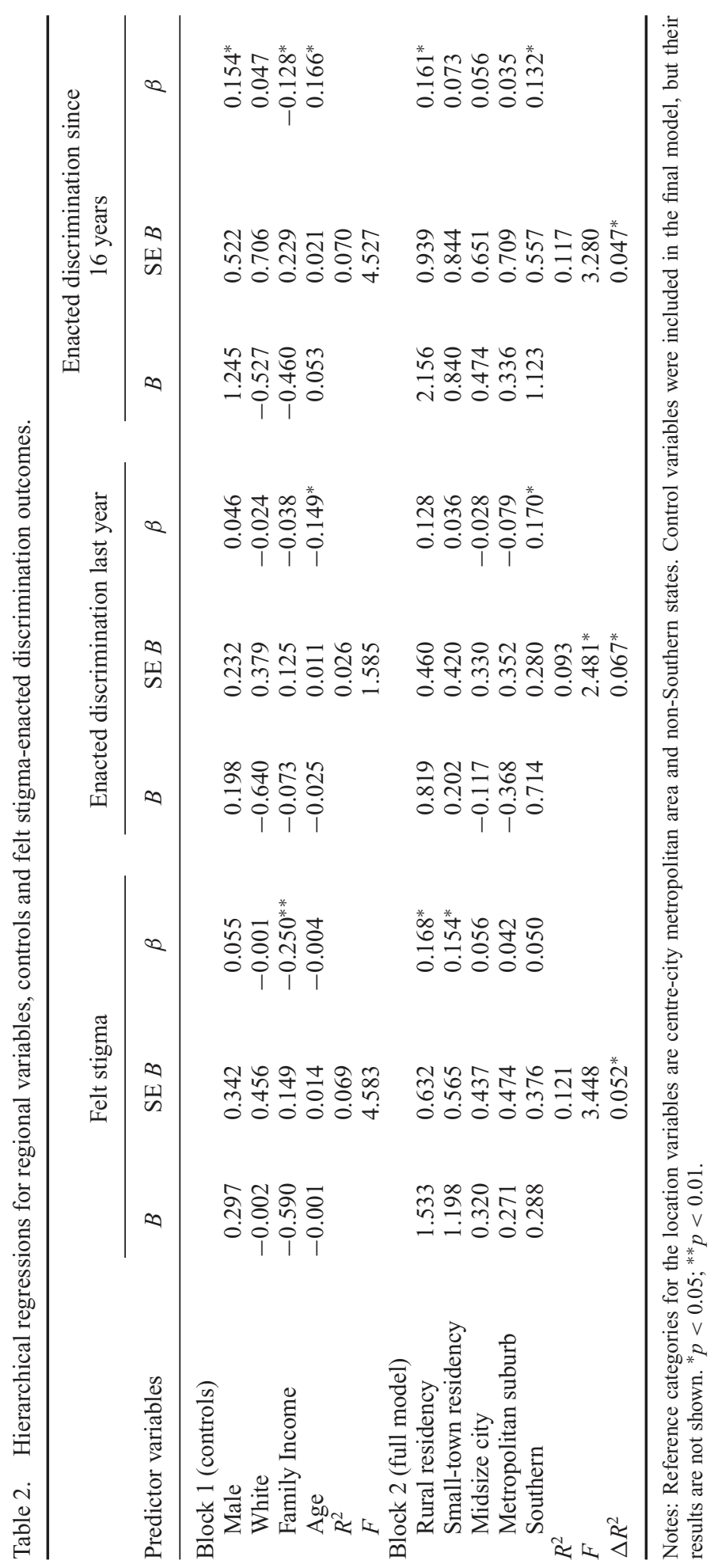


Table 3. Hierarchical regressions for regional variables, controls and community outcomes.

\begin{tabular}{lccc}
\hline & \multicolumn{3}{c}{ LGB community connectedness } \\
\cline { 2 - 4 } Predictor variables & $B$ & SE $B$ & $\beta$ \\
\hline Block 1 (controls) & & & \\
$\quad$ Male & 0.055 & 0.255 & 0.013 \\
$\quad$ White & 0.597 & 0.337 & 0.109 \\
Family Income & 0.386 & 0.111 & $0.215^{*}$ \\
$\quad$ Age & 0.011 & 0.010 & 0.066 \\
$R^{2}$ & & 0.072 & \\
$F$ & & $4.911^{*}$ & $-0.120^{* *}$ \\
Block 2 (full model) & & & -0.111 \\
$\quad$ Rural residency & -0.797 & 0.430 & -0.034 \\
Small-town residency & -0.648 & 0.383 & -0.012 \\
$\quad$ Midsize city & -0.170 & 0.338 & $-0.166^{* *}$ \\
Metropolitan suburb & -0.061 & 0.327 & \\
Southern & -0.711 & 0.264 & \\
$R^{2}$ & & 0.118 & $3.690^{*}$ \\
$F$ & & $0.046^{* *}$ & \\
$\Delta R^{2}$ & & & \\
\hline
\end{tabular}

Notes: Reference categories for the location variables are centre-city metropolitan area and non-Southern states. Control variables were included in the final model, but their results are not shown. ${ }^{*} p<0.05 ;{ }^{* *} p<0.01$.

Southern location (regardless of rurality and other control variables) was further associated with heightened exposure to discrimination (both in the past year and since age 16) compared with living in other parts of the United States ( $\beta$ values ranged from 0.170 to 0.132 , $p<0.05)$.

\section{Place variables and psychological connectedness to the lesbian, gay, bisexual and transgender community}

Results of tests for location differences in feelings of connectedness to an LGB community are presented in Table 3. With significant coefficients of determination for both blocks of variables, it is clear that the spatial factors explained unique variance in participants' sense of closeness to an LGB community above and beyond the control variables $\left(R^{2}=0.072\right.$ and 0.118 for both blocks and $\Delta R^{2}$ of 0.046 for the spatial factors). Living in a rural location was associated with lower levels of community connectedness compared with living in a centre city $(\beta=-0.120 p<0.05)$. Additionally, living in the Southern United States was further associated with lower levels of community connectedness compared with living in another part of the United States $(\beta=-0.166, p<0.05)$.

\section{Discussion}

This study addressed possible relationships between location of residency and exposure to minority stress. Specifically, we analysed that the ways living in different types of communities were connected to four elements of the experience of minority stress among self-identified LGB individuals: felt stigma, enacted discrimination - short and long terms - and feelings of connectedness to an LGB community. In several instances, results indicated a greater prevalence of minority stress in small towns and rural settings compared with urban environments. The largest impact of living in these communities was found 
regarding felt stigma and long-term experiences of enacted discrimination. Specifically, rural and small-town LGBs were more likely to endure a history of subtle discrimination and rural individuals encountered more lifetime discrimination. Conversely, rural and small-town LGBs did not report significantly higher levels of recent discrimination. This difference in significance for lifetime and recent levels of discrimination could be due to an improvement in rural conditions in the past decades or it could be an artefact of methodological problems like too small of a sample size or focusing on the wrong types of discrimination. Clearly, longitudinal data are required to address a relative improvement for rural participants over time. Rural LGBs not only reported greater stigma, but also were more isolated and disconnected from communities that may provide affirmation of their sexual identities, as evidenced by lower levels of community connectedness among rural-living LGBs compared with urban dwelling LGBs. This again supports the argument that centre cities may partially insulate LGBs from some of the felt stigma and isolation that rural communities impose upon sexual minorities.

Dwelling in mid-sized cities and the suburbs was not associated with any aspect of minority stress. Although these locations displayed more minority stress than their centrecity counterparts, these differences were not substantial or statistically significant. On the other hand, a Southern residency presented several important ramifications for LGBs. Importantly, Southerners reported higher levels of recent and lifetime enacted discrimination and less connection to the LGB community. These findings clearly suggest that the South is a harsher place for sexual minorities than other regions of the United States.

Although the associations between location and minority stress were our primary focus in this study, some other notable findings emerged regarding our control variables of gender, race/ethnicity, income and age. In most cases, the effects of control variables on minority stress were not significant. However, gender occasionally mattered, as gay and bisexual men dealt with more enacted discrimination in their lifetime than lesbian and bisexual women. Further, higher income was associated with fewer experiences of felt or long-term discrimination and greater connections to the LGB community. This suggests that gay and bisexual men and poorer sexual minorities might be targeted more for discrimination and may have less of the vital resources that assist in the avoidance of discrimination. Age and when people were exposed to discrimination had opposite directions in this study. Younger sexual minorities experienced more recent discrimination, but older sexual minorities experienced a larger amount of lifetime discrimination. The link between older age and lifetime discrimination suggests that older individuals may not experience active discrimination, but they may have lived through years when homophobia and heterosexism were more explicit, rampant and publicly condoned. Further, older LGBs had greater opportunity to be exposed to discrimination, given they have lived more years since age 16 than younger LGBs. Thus, the association between age and long-term discrimination should not be interpreted beyond its role as a control variable in the present analyses.

Although we did not examine indicators of LGB health in this study, our findings have significant implications for the larger body of literature examining the connection between minority stress and health. Specifically, rural geographic location represents an important risk factor for increased exposure to some forms of minority stress beyond other disadvantaged social statuses (e.g. gender, race/ethnicity, income, age). Thus, geographic location needs to be considered in larger models of social stress and minority stress due to its potential implications for the overarching relationship between stress and health among sexual minorities (see Meyer et al., 2008). Even further, rural location limits community coping resources; thus, rural-living LGBs' resources to cope with minority stressors are further 
limited by location, making negative health implications potentially more likely to result from minority stress exposure.

\section{Limitations}

These findings should be interpreted in the light of several study limitations. Some of the biggest measurement limitations could be found in the ability of respondents to detect, label and remember discriminatory experiences. Although some behaviours are considered obviously discriminatory to all observers, some of most insidious discriminatory actions transpire in ambiguous or confusing situations (e.g. adolescent boys' use of 'fag' as a form of salutation; Major \& Sawyer, 2009). When determining whether an action is discriminatory or not, people often reflect upon a long list of questions: Who is doing the discrimination? Is the behaviour considered harmful and intentional? Is the possible discriminator a member of a respected or disliked group? Does the respondent think the victim deserves the discrimination? Clearly, the answers to such questions are sometimes dependent on the characteristics of individual observers, so it would be safe to assume that the measures of felt and enacted discrimination could have problems with reliability and validity. Future research should include a wider range of stress measures, including both subjective and objective methods. Our measures of minority stress are not always 'place-specific,' so it is possible that a person who lives in a rural area could have experienced discrimination in another geographical area. Furthermore, we used shortened measures of minority stress in order to reduce participant burden and increase the feasibility of the online survey. Future studies should be conducted to replicate our findings using measures that have more extensive histories of psychometric soundness.

People may also differ in their definitions of what is rural or where the boundaries of centre cities and suburbs begin or end in large metropolitan areas. Also, because place of residency is not always constant, a measure of current residency may not reflect the amount of exposure to minority stress in previous locations. Accordingly, some people may have been classified as urban, small town or rural, although the discrimination could have occurred elsewhere (e.g. a recent migrant to a metropolitan area may have remembered discrimination that transpired in that person's teenage rural years). This study would also have been improved if we included a measure that distinguished bisexuals from lesbians and gays.

Although online surveys offered some advantages in the study of LGB populations, they are not without limitations. For example, our choice of listservs generated a higher proportion of respondents from some states (Kentucky and Ohio). The use of an Internetbased survey may introduce other sorts of selection bias since computer usage can vary by age, social class and race. This study had a low percentage of African Americans and high percentage of Native Americans. Likewise, the use of Internet sources can underestimate the proportion of sexual minorities who are more concealed about their sexual orientation. Also, the use of listservs might influence the findings on community connectedness because everyone in the sample was at least connected to other LGBs through an electronic network. However, this limitation does not justify dismissing these findings, given the demographic characteristics of online and mail samples of LGBs have been demonstrated to be 'practically indistinguishable' and 'equivalent' (Koch \& Emery, 2002; Riggle et al., 2005). The smaller sample size has also some limitations. With a larger number of participants, we could have tested for interaction effects between our spatial factors, as the cell size was too small to permit statistical power to detect if rural or small-town Southerners significantly differed from metropolitan Southerners. Finally, caution should 
be taken in generalising these findings to other countries. Studies do find cross-national variations in the acceptance and treatment of gays and lesbians (Adamczyk \& Pitt, 2009; Štulhofer \& Rimac, 2009), with the United States being more heteronormative than several European countries but much less than countries on other continents.

The $\beta$ coefficients of the location and regional differences in minority stress are small to moderate. We do not consider this to be surprising; many factors in addition to location may affect exposure to minority stress that are not included in this study. Further, the goal of this study was not to explain variance in these constructs, but instead to examine location and regional differences in LGBs' experiences of minority stress. As a result, small to moderate yet statistically significant differences in minority stress exposure are of practical significance, especially given that many of these differences remained significant after controlling for demographic and Socio-Economic Statuses (SES) factors.

Finally, this study probably overlooks some factors that matter in the spatial distribution of minority stress (Adamczyk \& Pitt, 2009). Suggesting some possible extraneous factors, rural states produced more lesbian, gay, bisexual and transgender (LGBT) hate crimes until one controls for poverty rates and the presence of gay-lesbian community centres (Van Dyke et al., 2001). Also, Southern states embrace greater gender conservatism because they contain higher concentrations of poor religious fundamentalists who have less access to higher education (Moore \& Vanneman, 2003).

\section{Conclusions}

In sum, this study offers some unique yet preliminary findings that highlight the role of rural location in LGBs' experiences of minority stress and community connectedness. By being the first study to systematically examine the urban-rural continuum and exposure to minority stress, this study provides new insights into the relationship between the geographical location and the lives of sexual minorities. These findings certainly suggest that future research should interrogate some of the common assumptions about rural locations as toxic spaces for LGBs and urbanity as an idealised space for LGBs; our results suggest a more complicated picture. In addition, the assumption that the South provides a particularly hostile environment for LGBs was mostly supported, highlighting yet another regional risk factor for minority stress that future research should continue to investigate. Certainly, the complicated relationship between minority stress and location of residence emphasises the importance of striving for contextual understandings of LGB individuals' lives in their social and spatial milieu.

\section{Acknowledgements}

The authors thank Dr. Bernadette Barton, Michele Fiore and Jessica Roe for their assistance in the gathering of data for this study.

\section{Note}

1. This sampling technique was devised because this study came out of a project that was also trying to examine political activism among gays and lesbians (Swank \& Fahs, in press).

\section{Notes on contributors}

Eric Swank is Associate Professor of Social Work at Morehead State University. His sexuality publications explore the relationship between social hierarchies and sexual satisfaction for women as well as sexual prejudice among rural residents. Recently, he has published on political participation among lesbians and gays (Sexuality Research \& Social Policy) and 'ally' activism among heterosexuals (Journal of Homosexuality), and has a forthcoming study on the intersections of race, gender and sexuality in political activism (Sex Roles). 
David M. Frost is Assistant Professor of Population and Family Health at Columbia University. His research focuses on how stigma, prejudice and discrimination constitute minority stress and, as a result, affect the health and well-being of marginalised individuals. His work on stigma and minority stress has been recognised by grants and awards from the National Institutes of Health, the Society for the Psychological Study of Social Issues and the New York Academy of Sciences. He received his Ph.D. in social and personality psychology from the Graduate Center of the City University of New York.

Breanne Fahs is Associate Professor of Women and Gender Studies at Arizona State University specialising in research on women's sexualities, critical embodiment studies, radical feminism and political socialisation. Her recent book Performing Sex: The Making and Unmaking of Women's Erotic Lives (SUNY Press, 2011) interrogated women's struggles with sexual 'liberation', while her next book examines the life and work of author and would-be assassin, Valerie Solanas. She also works as a practicing clinical psychologist specialising in sexuality, LGBTQ issues, gender identity and trauma recovery.

\section{References}

Adamczyk, A., \& Pitt, C. (2009). Shaping attitudes about homosexuality: The role of religion and cultural context. Social Science Research, 38, 338-351.

Barton, B. (2010). 'Abomination' life as a bible-belt gay. Journal of Homosexuality, 57, 464-484.

Bell, D., \& Valentine, G. (1995). Queer country: Rural lesbian and gay lives. Journal of Rural Studies, $11,113-122$.

Black, K., \& Rhorer, M. (2001). Out in the mountains: Exploring gay and lesbian lives. In C.L. Dews \& C.L. Law (Eds.), Out in the South (pp. 16-25). Philadelphia, PA: Temple University Press.

Bolzendahl, C.I., \& Myers, D.J. (2004). Feminist attitudes and support for gender equality: Opinion change in women and men, 1974-1988. Social Forces, 83, 759-790.

Boulden, W. (2001). Gay men living in a rural environment. Journal of Gay and Lesbian Social Services 12, 63-75.

Brooks, V. (1981). Minority stress and lesbian women. Lexington, KY: Lexington Press.

Butler, R. (1999). Double the trouble or twice the fun? Disabled bodies in the gay community. In R. Butler \& H. Parr (Eds.), Mind and body spaces: Geographies of illness, impairment and disability (pp. 203-220). London: Routledge.

Carter, J.S., \& Borch, C.A. (2005). Assessing the effects of urbanism and regionalism on gender-role attitudes. Sociological Inquiry, 75, 548-565.

Chalfant, H.P., \& Heller, P.L. (1991). Rural/urban versus regional differences in religiosity. Review of Religious Research, 33, 76-86.

Cody, P.J., \& Welch, P.J. (1997). Rural gay men in northern New England. Journal of Homosexuality, $33,51-68$.

Crocker, J., \& Major, B. (1989). Social stigma and self-esteem: The self-protective properties of stigma. Psychological Review, 96(4), 608-630.

DiPlacido, J. (1998). Minority stress among lesbians, gay men, and bisexuals: A consequence of heterosexism, homophobia, and stigmatization. In G.M. Herek (Ed.), Stigma and sexual orientation: Understanding prejudice against lesbians, gay men, and bisexuals (pp. 138-159). Thousand Oaks, CA: Sage.

Dohrenwend, B.P. (2000). The role of adversity and stress in psychopathology: Some evidence and its implications for theory and research. Journal of Health \& Social Behavior, 41, 1-19.

Eldridge, V., Mack, L., \& Swank, E. (2006). Explaining comfort with homosexuals in rural America. Journal of Homosexuality, 51, 39-56.

Ellison, C.G. (1991). An eye for any eye? A note on the Southern subculture of violence. Social Forces, 69, 1223-1239.

Farquhar, C. (1999). Are focus groups suitable for 'sensitive' topics? In R. Barbour \& J. Kitzinger (Eds.), Developing focus group research: Politics, theory and practice (pp. 46-63). London: Sage.

Faugier, J., \& Sargeant, M. (1997). Sampling hard to reach populations. Journal of Advanced Nursing, 26, 790-797.

Fellows, W. (1998). Farm boys: Lives of gay men in the rural Midwest. Madison, WI: University of Wisconsin Press. 
Fischer, C.S. (1975). Toward a subcultural theory of urbanism. American Journal of Sociology, 80, 1319-1341.

Frost, D.M., \& Meyer, I.H. (2012). Measuring community connectedness among diverse sexual minority populations. Journal of Sex Research, 48(1), 36-49.

Galliher, R.V., Rostosky, S.S., \& Hughes, H.K. (2004). School belonging, self-esteem, and depressive symptoms in adolescents: An examination of sex, sexual attraction status, and urbanicity. Journal of Youth and Adolescence, 33, 235-245.

Gonzalez, A., Miller, C.T., Solomon, S.E., Bunn, J.Y., \& Cassidy D.G. (2009). Size matters: Community size, HIV status, and gender differences. AIDS Behavior, 13, 1205-1212.

Gottschalk, L., \& Newton, J. (2009). Rural homophobia. Gay \& Lesbian Issues and Psychology Review, 5, 153-159.

Gray, M.L. (2009). Out in the country: Youth, media and queer visibility in rural America. New York: NYU Press.

Hatzenbuehler, M.L. (2010). Social factors as determinants of mental health disparities in LGB populations: Implications for public policy. Social Issues and Policy Review, 4, 31-62.

Herek, G.M. (2002). Heterosexuals' attitudes toward bisexual men and women in the United States. Journal of Sex Research, 39, 264-274.

Herek, G.M. (2009). Hate crimes and stigma-related experiences among sexual minority adults in the United States. Journal of Interpersonal Violence, 24, 54-74.

Herek, G.M., \& Glunt, E. (1993). Interpersonal contact and heterosexual's attitudes toward gay men. The Journal of Sex Research, 30, 239-244.

Herek, G.M., \& Glunt, E.K. (1995). Identity and community among gay and bisexual men in the AIDS era: Preliminary findings from the Sacramento Men's Health Study. In G.M. Herek \& B. Greene (Eds.), AIDS, identity, and community: The HIV epidemic and lesbians and gay men (pp. 55-84). Thousand Oaks, CA: Sage Publications, Inc.

Hewitt, M. (1992). Defining rural areas: Impact on health care policies and research. New Brunswick, NJ: Rutgers University Press.

Hyers, L.L. (2007). Resisting prejudice every day: Exploring women's assertive responses to antiblack racism, anti-Semitism, heterosexism, and sexism. Sex Roles, 56, 1-12.

Jennings, M.K., \& Andersen, E.A. (2003). The importance of social and political context: The case of AIDS activism. Political Behavior, 25, 177-199.

Johnson, M., Jackson, N., Arnette, J.K., \& Koffman, S. (2005). Gay and lesbian perceptions of discrimination in retirement care facilities. Journal of Homosexuality, 49, 83-102.

Johnson, N.E. (1999). Nonmetropolitan sex role ideologies. Rural Sociology, 64, 44-65.

Johnson, N.E., \& Stokes, C.S. (1984). Southern traditionalism and sex role ideology: A research note. Sex Roles, 10, 11-18.

Kertzner, R., Meyer, I., Frost, D., \& Stirratt, M. (2009). Social and psychological well-being in lesbians, gay men, and bisexuals: The effects of race, gender, age, and sexual identity. American Journal of Orthopsychiatry, 79(4), 500-510.

Kinsey, A., Pomeroy, W., \& Martin, C. (1948). Sexual behavior in the human male. Philadelphia, PA: W.B. Saunders.

Koch, N.S., \& Emery, J.A. (2002). The internet and opinion measurement: Surveying marginalized populations. Social Science Quarterly, 82, 131-138.

Konrad, A.M., \& Harris, C. (2002). Desirability of the Bem sex-role inventory for men and women: A comparison between African Americans and European Americans. Sex Roles, 47, 259-271.

Kosciw, J.G., Greytak, E.A., \& Diaz, E.M. (2009). Who, what, where, when, and why: Demographics and ecological factors contributing to hostile school climates for lesbian, gay, bisexual and transgender youth. Journal of Youth and Adolescence, 30, 976-988.

Kramer, J.L. (1995). Bachelor farmers and spinsters: Gay and lesbian identities and communities in rural North Dakota. In V. Bell \& G. Valentine (Eds.), Mapping desire: Geographies of desire (pp. 182-194). London: Routledge.

Lamelle, A., \& Battle, J. (2004). Black masculinity matters in attitudes toward gay male. Journal of Homosexuality, 47, 39-51.

Leedy, G., \& Connolly, C. (2007). Out in the cowboy state: A look at lesbian and gay lives in Wyoming. Journal of Gay \& Lesbian Social Services, 19, 17-34.

Lewis, N.M. (2009). Mental health in sexual minorities: Recent indicators, trends, and their relationships to place in North America and Europe. Health \& Place, 15, 1029-1045.

Loftus, J. (2001). America's liberalization in attitudes toward homosexuals. American Sociological Review, 66, 762-782. 
Major, B., \& O’Brien, L. (2005). The social psychology of stigma. Annual Review of Psychology, $56,393-421$.

Major, B., \& Sawyer, P.J. (2009). Attributes to discrimination. In T.D. Nelson (Ed.), Handbook of prejudice, stereotyping, and discrimination (pp. 89-110). New York: Psychology Press.

Marquart, B.S., Nannini, D.K., Edwards, R.W., Stanley, L.R., \& Wayman, J.C. (2007). Prevalence of dating violence and victimization: Regional and gender differences. Adolescence, 42, 645-657.

Marsiglio, W. (1993). Attitudes toward homosexual activity and gays as friends. Journal of Sex Research, 30, 12-17.

McCarthy, L. (2000). Poppies in a wheat field: Exploring the lives of rural lesbians. Journal of Homosexuality, 39, 75-90.

Meyer, I.H. (2003a). Prejudice, social stress, and mental health in lesbian, gay, and bisexual populations: Conceptual issues and research evidence. Psychological Bulletin, 129, 674-697.

Meyer, I.H. (2003b). Prejudice as stress: Conceptual and measurement problems. American Journal of Public Health, 93, 262-265.

Meyer, I.H., Schwartz, S., \& Frost, D.M. (2008). Social patterning of stress and coping: Does disadvantaged social status confer more stress and fewer coping resources? Social Science \& Medicine, 67, 368-379.

Miller, M., \& Luloff, A.E. (1981). Who is rural? Rural Sociology, 46, 608-625.

Moore, L., \& Vanneman, R. (2003). Gender matters: Effects of proportion fundamentalist on gender attitudes. Social Forces, 82, 115-139.

Nisbett, R.E., \& Cohen, D. (1996). Culture of honor: The psychology of violence in the South. Boulder, CO: Westview Press.

Oswald, R.F., \& Culton, L.S. (2003). Under the rainbow: Rural gay life and its relevance for family providers. Family Relations: An Interdisciplinary Journal of Applied Family Studies, 52, 72-81.

Pearlin, L.I. (1999). The Stress process revisited: Reflections on concepts and their interrelationships. In C.S. Aneshensel \& J.C. Phelan (Eds.), Handbook on the Sociology of Mental Health (pp. 395-415). New York: Plenum Press.

Poon, C.S., \& Saewyc, E.M. (2009). Out yonder: Sexual-minority adolescents in rural communities in British Columbia. American Journal of Public Health, 99, 118-124.

Powers, R.S., Suitor, J.J., Guerra, S., Shackelford, M., Mecom, D., \& Gusman, K. (2003). Regional differences in gender-role attitudes: Variation by gender and race. Gender Issues, 21, 41-54.

Pratte, T. (1993). A comparative study of attitudes toward homosexuality. Journal of Homosexuality, 26, 77-83.

Puckett, J.A., Horne, S.G., Levitt, H.M., \& Reeves, T. (2011). Out in the country: Rural sexual minority mothers. Journal of Lesbian Studies, 15, 176-186.

Rhoads, R.A. (1997). Crossing sexual orientation borders: Collaborative strategies for dealing with issues of positionality and representation. Qualitative Studies in Education, 10, 7-23.

Rhodebeck, L.A. (1996). The structure of men's and women's feminist orientations. Gender \& Society, 10, 386-403.

Rice, T.W., \& Coates, D.L. (1995). Gender role attitudes in the southern United States. Gender \& Society, 9, 744-756.

Riggle, E.D.B., Rostosky, S.S., \& Reedy C.S. (2005). Online surveys for BGLT research: Issues and techniques. Journal of Homosexuality, 49, 1-21.

Rosario, M., Schrimshaw, E., Hunter, J., \& Gwadz, M. (2002). Gay-related stress and emotional distress among gay, lesbian and bisexual youths: A longitudinal examination. Journal of Consulting and Clinical Psychology, 70, 967-975.

Schulte, L. (2002). Similarities and differences in homophobia among African Americans and Caucasians. Race, Gender \& Class, 9, 71-93.

Štulhofer, A., \& Rimac, I. (2009). Determinants of homonegativity in Europe. Journal of Sex Research, 46, 24-32.

Swank, E., \& Fahs, B. (2011). Pathways to political activism among Americans who have same-sex sexual contact. Research in Sexuality \& Social Policy, 8, 126-138.

Swank, E. \& Fahs, B. (in press). Predicting electoral activism among gays and lesbians in the United States. Journal of Applied Social Psychology.

Szymanski, D., Chung, B., \& Balsam, K. (2001). Psychological correlates of internalized homophobia in lesbians. Measurement and Evaluation in Counseling and Development, 34, $27-41$. 
Taylor, V., Kimport, K., Van Dyke, N., \& Andersen E.A. (2009). Culture and mobilization: Tactical repertoires, same-sex weddings, and the impact on gay activism. American Sociological Review, $74,865-890$.

Tiemann, K.A., Kennedy, S.A., \& Haga, M.P. (1998). Rural lesbians' strategies for coming out to health care professionals. Journal of Lesbian Studies, 2, 61-75.

Twenge, J.M. (1997). Attitudes toward women, 1970-1995: A meta-analysis. Psychology of Women Quarterly, 21, 35-51.

Van Dyke, N., Soule, S., \& Windom, R. (2001). The politics of hate: Explaining variation in the incidence of anti-gay hate crime. Research in Political Sociology, 9, 35-58.

Waldo, C.R., Hesson-McInnnis, M.S., \& D’Augelli, A.R. (1998). Antecedents and consequences of victimization of lesbian, gay, and bisexual young people: A structural model comparing rural university and urban samples. American Journal of Community Psychology, 26, 307-333.

Willging, C.E., Salvador, M., \& Kano, M. (2006). Pragmatic help seeking: How sexual and gender minority groups access mental health care in a rural state. Psychiatric Services, 57, 871-874.

Williams, M.L., Bowen, A.M., \& Horvath, K.J. (2005). The social/sexual environment of gay men residing in a rural frontier state. Journal of Rural Health, 21, 48-55.

Wirth, L. (1938). Urbanism as a way of life. American Journal of Sociology, 44, 1-24.

Woodberry, R.D., \& Smith, C.S. (1998). Fundamentalism et al.: Conservative Protestants in America. Annual Review of Sociology, 24, 25-56.

Yarbrough, D.G. (2003). Gay adolescents in rural areas: Experiences and coping strategies. Journal of Human Behavior in the Social Environment, 8, 129-144. 